\title{
Understanding and Addressing the Unaccompanied Minor Immigration Issue ${ }^{1}$
}

\author{
By Ernesto F. L. Amaral and Daniel M. Gerstein \\ April 21, 2016, at 11:49 a.m.
}

After declining sharply in 2015, the number of unaccompanied child immigrants apprehended at the U.S. southwest border appears to be on the rise again, a development that has the potential to reignite debate over what the United States should do about the plight of these young and vulnerable illegal immigrants.

To properly consider this complex issue, it is essential to understand the changes that have occurred over time in the immigration landscape. A good place to start is a close examination of data gleaned from interviews with unaccompanied immigrant children conducted by U.S.

Customs and Border Protection personnel. Gathering and analyzing other data also could help policymakers develop initiatives to make it easier for young immigrants to integrate into American society.

The number of unaccompanied children, 17 or younger, apprehended at the U.S. Southwest border increased dramatically from about 18,400 in fiscal year 2010 to 68,500 four years later. The number dropped to just under 40,000 during fiscal 2015 then increased significantly during the first five months of fiscal 2016 —apprehensions nearly doubled, from 12,490 to about 23,550 , over the same period in the previous fiscal year.

Children tend to attempt illegal immigration based on a variety of socioeconomic and security issues, including poverty, economic distress, crime, violence, and to pursue family reunification. But when they are sent off alone, they face even more uncertain futures and many dangers, often at the hands of ruthless human smugglers.

"The desire to see a child have a better life in the United States is understandable," Department of Homeland Secretary Jeh C. Johnson said in a 2014 open letter aimed at parents considering sending their kids to the United States alone. "But, the risks of illegal migration by an unaccompanied child to achieve that dream are far too great, and the 'permisos' (permits) do not exist," he wrote.

The majority of unaccompanied children coming across the U.S.-Mexico border are not from Mexico, but from Central America. Of those apprehended during the five-month period ending Feb. 29, nearly 80 percent came from El Salvador, Honduras and Guatemala.

The governments of these countries, with support from the United States, are implementing the Plan for the Alliance for Prosperity in the Northern Triangle. Its goal is to stem the exodus of both adults and children by stimulating economic growth, reducing inequality, promoting educational opportunities, targeting criminal networks responsible for human trafficking, and creating governance and institutions that are transparent and accountable. But more needs to be done here in the United States.

Given the realities on the ground, the most relevant questions should perhaps focus on promoting integration of unaccompanied minors into U.S. society. What qualities lead to

\footnotetext{
${ }_{1}^{1}$ Amaral EFL, Gerstein DM. 2016. "Understanding and addressing the unaccompanied minor immigration issue." Congress Blog - The Hill's Forum for Lawmakers and Policy Professionals, April 21, 2016. (The Hill link)
} 
successful integration? Are there specific indicators that determine whether an unaccompanied minor will be successfully integrated? What policies can be implemented to maximize these chances? What are their long-term prospects with host families, which can include parents, relatives and non-family relations? How are these children adapting in their schools and communities?

Some background could be found in interviews of unaccompanied children immigrants that are routinely conducted after they are apprehended. This information could provide insights that might help in developing strategies to deal with both security and humanitarian issues. More indepth interviews at the border and follow-up interviews could help broaden the understanding of these youths' prospects for success.

Other data also could serve as a resource. Currently, information from censuses and surveys does not necessarily capture data on whether immigrant children entered the country with or without parents and relatives. As a result, little is known about how this affects the integration of these children into American society. Expanding this data collection in areas that have historically released the highest numbers of these children to sponsors-such as Los Angeles County; Harris County, Texas; Prince George's County, Maryland.; and Palm Beach County, Florida-could be promising.

Integration among all immigrants, young and old, has been occurring fairly well in terms of language proficiency, socioeconomic status, household location, political participation, and social networks, according to the Migration Policy Institute and others. Yet successful integration can take more than one generation, as children of immigrants move toward improved socioeconomic and educational outcomes. This suggests the integration process should be more closely watched over time, to analyze whether unaccompanied immigrant children integrate as well as those who come to the United States with their parents.

Research could provide valuable information to policymakers through analyses that explore qualitative and quantitative data about immigrant children. Tools exist to develop such studies by exploring data from Customs and Border Protection interviews, implementing surveys that capture status of unaccompanied minors and conducting longitudinal studies to follow children over time. Mining this data could benefit policymakers as they try to find a way to help young immigrants to America who journeyed north alone.

Ernesto F. L. Amaral (eflamaral@gmail.com) is an associate sociologist at the nonprofit, nonpartisan RAND Corporation. His research projects deal with the estimation and analysis of migration, effects of demographic transition on labor markets and evaluation of public policies.

Daniel M. Gerstein (Daniel Gerstein@rand.org) works at the nonprofit, nonpartisan RAND Corporation. He was the former Under Secretary (Acting) and Deputy Under Secretary in the Science and Technology Directorate of the Department of Homeland Security from 2011-2014. 